\title{
UTILITY OF OTOLITH WEIGHT TO ESTIMATE AGE OF LABEO BATA (ACTINOPTERYGII: CYPRINIFORMES: CYPRINIDAE) INHABITING THE GANGA RIVER
}

\author{
M. Afzal KHAN*, Aafaq NAZIR, and Umarah Zahoor BANDAY \\ Section of Fishery Science and Aquaculture, Department of Zoology, Aligarh Muslim University, Aligarh, India
}

\begin{abstract}
Khan M.A., Nazir A., Banday U.Z. 2018. Utility of otolith weight to estimate age of Labeo bata (Actinopterygii: Cypriniformes: Cyprinidae) inhabiting the Ganga River. Acta Ichthyol. Piscat. 48 (3): $257-260$.
\end{abstract}

\begin{abstract}
Fish age estimation is essential for stock assessment, population dynamics, and fisheries management. The presently reported study was conducted to evaluate the relation between otolith weight and observed age in Labeo bata (Hamilton, 1822) inhabiting the Ganga River. A total of 187 L. bata specimens were collected from Narora site of the Ganga River. Linear regression analysis was applied between otolith weight and observed age to predict the age of fish from the otolith weight. The relation between otolith weight and observed age was significant for $L$. bata. The otolith weight increased with the fish age. Discriminant function analysis revealed $96.3 \%$ of the predicted ages were correctly classified to their observed ages. Thus, it can be inferred that the relation between otolith weight and fish age can provide an additional method of age estimation in L. bata.
\end{abstract}

Keywords: age estimation, otolith weight, predicted age, Labeo bata, Ganga River

\section{INTRODUCTION}

Age and growth of fish species is the basis for an understanding of the species biology and is highly significant for the management and conservation of the fisheries resources. Fish age estimation is also essential for stock assessment and population dynamics (Khan and Khan 2009). Fish age is generally estimated after initial preparation of the otolith (such as embedding, sectioning, and polishing) followed by microscopic examination and counts of the annual growth zones (annuli). The preparation process is generally time consuming and interpretation of the annuli requires expertise. As a result, the process of age determination from hard structures is very expensive (Francis and Campana 2004). Moreover, age validation methods increase precision and accuracy of age estimates (Campana 2001), but these methods require either markrecapture method or regular sampling of fish over relatively long time periods thereby are rarely completed (Britton and Blackburn 2014). The otolith weight increases continuously throughout the life of fish in contrast to otolith length and fish length (Fowler and Doherty 1992). Thus, in some cases (Fletcher 1995), otolith weight can be used as an effective surrogate for the age to reduce the cost and subjectivity associated with traditional annuli enumeration (Bermejo 2007, Britton and Blackburn 2014). However, there are reports of overlap in otolith weight among age classes that may lead to incorrect ageing of a number of individuals; this depends on the amount of overlap and on the abundance of each age class (Cardinale and Arrhenius 2004).
Labeo bata (Hamilton, 1822) has been reported from rivers and lakes of India, Bangladesh, and Pakistan (Talwar and Jhingran 1991). Labeo bata is a benthopelagic, potamodromous species and a herbivorous column feeder. It is a commercially important species for aquaculture and it has a high market value (Rema Devi and Ali 2011). Labeo bata has been listed as of least concern by the IUCN (Rema Devi and Ali 2011). Loss of habitat, overexploitation, water pollution and siltation may be some of the threats to wild populations of the species (Molur and Walker 1998).

Therefore, the objective of the present study was to evaluate the relation between otolith weight and observed age (calculated by reading annuli on otoliths) in Labeo bata inhabiting the Ganga River.

\section{MATERIAL AND METHODS}

A total of 187 Labeo bata specimens were collected by cast nets at Narora site $\left(27^{\circ} 30^{\prime} \mathrm{N}, 78^{\circ} 25^{\prime} \mathrm{E}\right)$ of the Ganga River between January to June 2016. The samples were transferred in an ice box to the laboratory where they were identified, measured (fish length, $\mathrm{cm}$ ), their otoliths removed, cleaned, and washed with distilled water. Otoliths were then dried at room temperature for $18 \mathrm{~h}$ before being weighed (nearest $\mathrm{mg}$ ).

Otoliths were analysed under a Nikon ${ }^{\circledR}$ SMZ745T Stereozoom microscope using both transmitted and reflected light in order to determine the precise age by the two age readers independently. Otoliths with unclear 
growth zones were grounded with 320-grit CarbiMet ${ }^{\circledR} 2$ Abrasive Discs to make the zones more distinct (Khan et al. 2016).

Precision was assessed by subjecting the data obtained by two independent age readers to calculate the mean percentage error and coefficient of variation. Mean percentage error $(\mathrm{MPE})^{*}$ was derived using the formula presented by Beamish and Fournier (1981)

$$
\mathrm{MPE}_{j}=100 \% \times \frac{1}{R} \sum_{i=1}^{R} \frac{\left|X_{i j}-X_{j}\right|}{X_{j}}
$$

where $X_{i j}$ is the $i$ th age determination of the $j$ th fish, $X_{j}$ is the mean age estimate of the $j$ th fish, and $R$ is the number of times each fish is aged. Coefficient of variation (CV), expressed as the ratio of the standard deviation over the mean, was computed following Chang (1982)

$$
\mathrm{CV}_{\mathrm{j}}=100 \% \times \frac{\sqrt{\sum_{i=1}^{R} \frac{\left(X_{i j}-X_{j}\right)^{2}}{R-1}}}{X_{j}}
$$

where $\mathrm{CV}_{\mathrm{j}}$ is the age precision estimate for the $j$ th fish.

Age bias graphs were plotted to examine potential bias between two independent age readers.

To predict the age of fish from otolith weight, linear regression analysis was applied between otolith weight and observed age (age obtained from counting annuli on the otoliths), that is

$$
T=\frac{\mathrm{OW}-a}{b}
$$

where $T$ is the estimated age (years), OW the otolith weight [mg], $a$ is the intercept and $b$ is the slope of linear regression between OW and observed age, respectively (Cardinale et al. 2000, Pino et al. 2004).

The discriminant function analysis was performed by using the observed age as a grouping variable and fish length and otolith weight as the independent variables. The discriminant functions were developed through crossvalidation classification by using the leave-one-out method and the use of this method means that the accuracy of age classifications are mean values (Ibáñez et al. 2008). The predicted ages and their related probability were the proportion of fish classified according to their relation between total length and otolith weight vs. their estimated age obtained from otoliths analysed under a stereo-zoom microscope by two independent readers (Britton and Blackburn 2014).

\section{RESULTS}

The number of samples, mean fish length, and mean otolith weight at each age, and comparison of MPE and $\mathrm{CV}$ within each age class for Labeo bata are shown in Table 1. There was no ageing bias observed between two independent readers for $L$. bata using otoliths (Fig. 1). Significant relations between otolith weight and fish age, and otolith weight and fish length were observed $\left(r^{2}>0.9\right.$, $P<0.001$ ) (Fig. 2). The discriminant function analysis for L. bata revealed the first canonical discriminant function elucidated $94.4 \%$ of variance and effectively separated the fish by age groups (Wilks $\lambda=0.05 ; P<0.001$ ).

The cross-validation classification method revealed $100 \%$ of individuals of the L. bata having same predicted age as the observed for the age 1, 3, and 4. For age 2, 95.2\% of the L. bata individuals showed the same predicted age as the observed (remaining percentage predicted as age 1). Moreover, $83.3 \%$ of the L. bata individuals showed predicted age as observed for the age 5 (remaining percentage

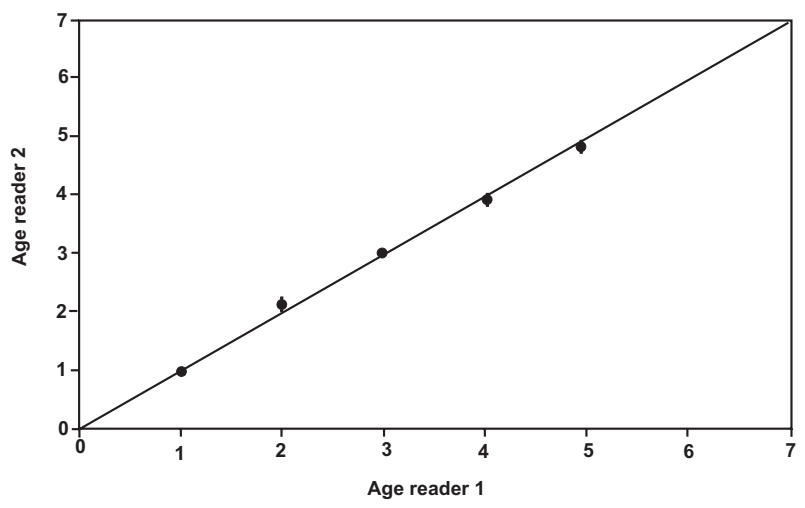

Fig. 1. Age bias plot for comparison of age estimates between two independent readers for otoliths in Labeo

\begin{tabular}{|c|c|c|c|c|c|}
\hline Age & $n$ & $\mathrm{TL}[\mathrm{cm}]$ & OW [mg] & MPE & $\mathrm{CV}$ \\
\hline 1 & 56 & $15.9 \pm 1.0$ & $1.93 \pm 0.08$ & 1.19 & 1.84 \\
\hline 2 & 43 & $20.9 \pm 1.0$ & $2.35 \pm 0.07$ & 1.41 & 1.97 \\
\hline 3 & 35 & $24.8 \pm 0.9$ & $2.98 \pm 0.06$ & 1.54 & 2.30 \\
\hline 4 & 33 & $29.7 \pm 0.8$ & $3.88 \pm 0.09$ & 1.78 & 2.77 \\
\hline 5 & 20 & $30.9 \pm 1.3$ & $4.40 \pm 0.12$ & 1.95 & 3.10 \\
\hline Total & 187 & & & 1.64 & 2.66 \\
\hline
\end{tabular}
bata from the Ganga River

Total length and otolith weight in consecutive age classes of Labeo bata from the Ganga River

$n=$ number of fish, $\mathrm{TL}=$ total length, $\mathrm{OW}=$ otolith weight, $\mathrm{MPE}=$ mean percentage error, $\mathrm{CV}=\mathrm{coefficient}$ of variation; values of total length and otolith weight represent the mean \pm standard error.

* The editor of this journal would like to acknowledge the contribution of Beamish and Fournier (1981) to ichthyology but at the same time he would like to suggest a replacement of the "average percentage error (APE)" with more appropriate "mean percentage error (MPE)". 
predicted as age 4) (Fig. 3). Overall, 96.3\% of the predicted ages were correctly classified to their observed ages.

\section{DISCUSSION}

The presently reported study provided an evidence of a linear relation between otolith weight and observed age in Labeo bata from the Ganga River. Several studies have reported a linear relation between otolith weight and observed age (Pino et al. 2004, Metin and İlkyaz 2008, Ghanbarzadeh et al. 2014). Earlier studies have emphasized that average otolith weight continues to increase with age, unlike certain other variables e.g., fish length, otolith length, etc. The growth of otoliths is different from the somatic growth rate and may simply be more strictly related to time and age (Reznick et al. 1989). Therefore, otolith weight may provide a more accurate estimate of age than the other variables and in some conditions may provide a reliable estimate of fish age than annuli counts of otolith (Worthington et al. 1995). For example, when the counts of annuli are unclear especially in older individuals due to the curvature of the edge and the annuli along the edge become crowded and are difficult to differentiate

\section{A}

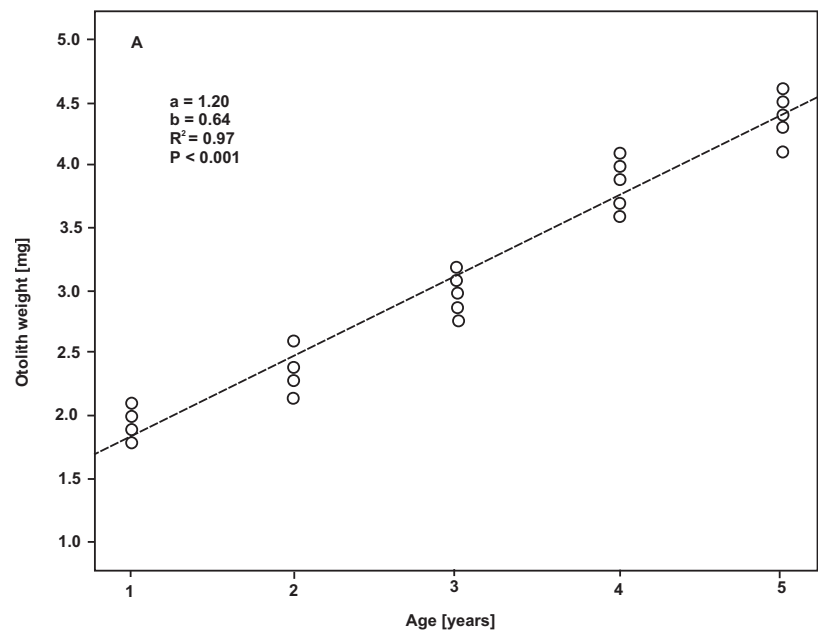

B

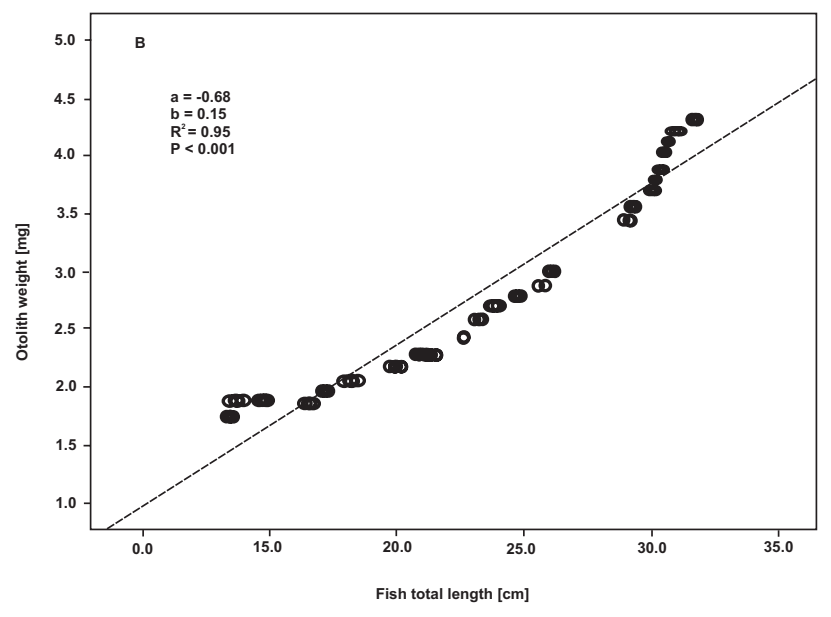

Fig. 2. Relation between otolith weight and fish age (A), and otolith weight and fish total length (B) of Labeo bata from the Ganga River

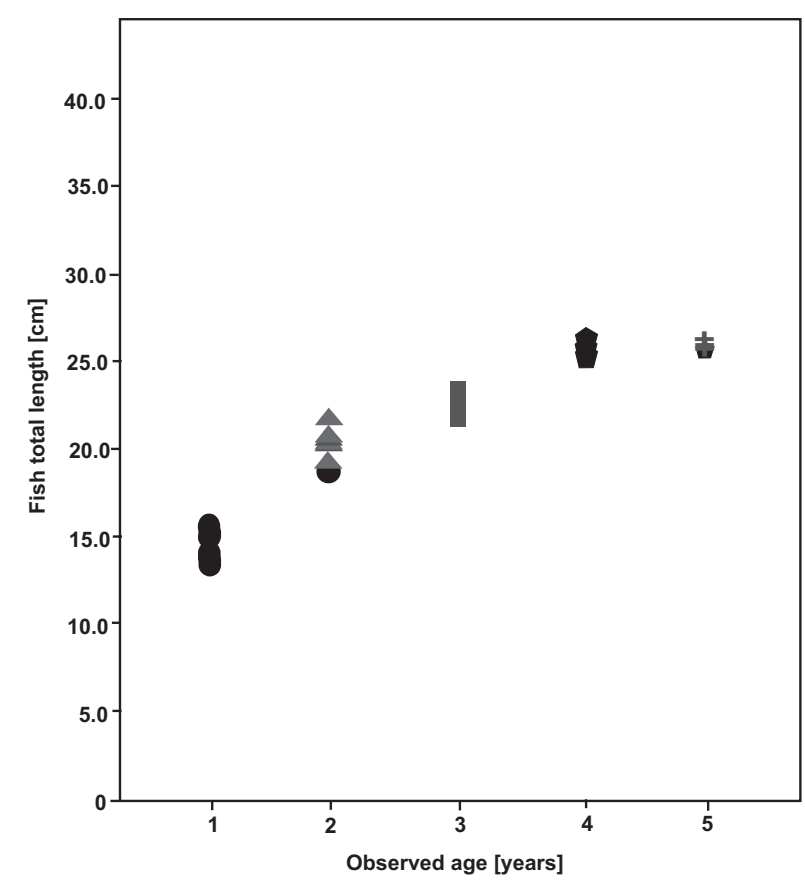

Fig. 3. Scatterplot showing contribution of predictive ages to the observed age for Labeo bata from the Ganga River; predicted age in years are represented by symbols; $1(\bullet), 2(\boldsymbol{\Delta}), 3(\boldsymbol{\bullet}), 4(\bullet)$, and $5(+)$

(Khan et al. 2016). In order to exploit the benefits of using otolith weight, the relation between otolith weight and observed age should be calibrated for each new sample of fish. The calibration would require precise age estimates of only a relatively small number of fish that should cover the whole range of the samples analysed.

The output of the predictive model (discriminant function analysis) revealed $96.3 \%$ of estimated ages were correctly classified to their ages obtained from microscopy. Thus, the predictive models can be used to estimate the age of fish with an output of the probability of the estimate without further use of microscopy and it implies strictly when there is no overlap in otolith weight between age classes (Britton and Blackburn 2014). We conclude that the relation between otolith weight and fish age can provide a substitute method of age estimation in Labeo bata.

\section{ACKNOWLEDGEMENTS}

The authors are grateful to the Chairman, Department of Zoology, Aligarh Muslim University, Aligarh, India for providing necessary facilities for this study.

\section{REFERENCES}

Beamish R.J., Fournier D.A. 1981. A method for comparing the precision of a set of age determinations. Canadian Journal of Fisheries and Aquatic Sciences 38 (8): 982-983. DOI: 10.1139/f81-132

Bermejo S. 2007. Fish age classification based on length, weight, sex and otolith morphological features. Fisheries Research 84 (2): 270-274. DOI: 10.1016/j. fishres.2006.12.007 
Britton J.R., Blackburn R. 2014. Application and utility of using otolith weights in the ageing of three flatfish species. Fisheries Research 154: 147-151. DOI: 10.1016/j.fishres.2014.02.005

Campana S.E. 2001. Accuracy, precision and quality control in age determination, including a review of the use and abuse of age validation methods. Journal of Fish Biology 59 (2): 197-242. DOI: 10.1111/j.10958649.2001.tb00127.x

Cardinale M., Arrhenius F. 2004. Using otolith weight to estimate the age of haddock (Melanogrammus aeglefinus):A tree model application. Journal of Applied Ichthyology 20 (6): 470-475. DOI: 10.1111/j.14390426.2004.00576.x

Cardinale M., Arrhenius F., Johnsson B. 2000. Potential use of otolith weight for the determination of agestructure of Baltic cod (Gadus morhua) and plaice (Pleuronectes platessa). Fisheries Research 45 (3): 239-252. DOI: 10.1016/S0165-7836(99)00122-8

Chang W.Y.B. 1982. A statistical method for evaluating the reproducibility of age determination. Canadian Journal of Fisheries and Aquatic Sciences 39 (8): 1208-1210. DOI: 10.1139/f82-158

Fletcher W.J. 1995. Application of the otolith weightage relationship for the pilchard, Sardinops sagax neopilchardus. Canadian Journal of Fisheries and Aquatic Sciences 52 (4): 657-664. DOI: 10.1139/f95066

Fowler A.J., Doherty P.J. 1992. Validation of annual growth increments in the otoliths of two species of damselfish from the southern Great Barrier Reef. Australian Journal of Marine and Freshwater Research 43 (5): 1057-1068. DOI: 10.1071/MF9921057

Francis R.I.C.C., Campana S.E. 2004. Inferring age from otolith measurements: A review and a new approach. Canadian Journal of Fisheries and Aquatic Sciences 61 (7): 1269-1284. DOI: 10.1139/f04-063

Ghanbarzadeh M., Soofiani N.M., Keivany Y., TaghaviMotlagh S.A. 2014. Use of otolith length and weight in age estimations of the kingsoldier bream, Argyrops spinifer, in the Persian Gulf. Iranian Journal of Ichthyology 1 (1): 1-6.

Ibáñez A.L., Britton J.R., Cowx I.G. 2008. Relationship between scale growth checks, circuli formation rate and somatic growth in Rutilus rutilus (L.) a fish farm- reared cyprinid. Journal of Fish Biology 72 (4): 1023 1034. DOI: $10.1111 / \mathrm{j} .1095-8649.2007 .01781 . \mathrm{x}$

Khan M.A., Khan S. 2009. Comparison of age estimates from scale, opercular bone, otolith, vertebrae and dorsal fin ray in Labeo rohita (Hamilton), Catla catla (Hamilton) and Channa marulius (Hamilton). Fisheries Research 100 (3): 255-259. DOI: 10.1016/j. fishres.2009.08.005

Khan M.A., Nazir A., Khan S. 2016. Assessment of growth zones on whole and thin-sectioned otoliths in Sperata aor (Bagridae) inhabiting the river Ganga, India. Journal of Ichthyology 56 (2): 242-246. DOI: $10.1134 / \mathrm{S} 0032945216020041$

Metin G., İlkyaz A.T. 2008. Use of otolith length and weight in age determination of poor cod (Trisopterus minutus Linn., 1758). Turkish Journal of Zoology 32 (3): 293-297.

Molur S., Walker S. (eds.) 1998. Report of the workshop "Conservation assessment and management plan for freshwater fishes of India". Zoo Outreach Organisation, Conservation Breeding Specialist Group (CBSG), Report No. 18, Coimbatore, India.

Pino C.A., Cubillos L.A., Araya M., Sepúlveda A. 2004. Otolith weight as an estimator of age in the Patagonian grenadier, Macruronus magellanicus, in central-south Chile. Fisheries Research 66 (2-3): 145-156. DOI: 10.1016/j.fishres.2003.07.003

Rema Devi K.R., Ali A. 2011. Labeo bata. The IUCN Red List of Threatened Species 2011: e.T166595A6243968. [Downloaded on 18 September 2017] DOI: 10.2305/ IUCN.UK.2011-1.RLTS.T166595A6243968.en

Reznick D., Lindbeck E., Bryga H. 1989. Slower growth results in larger otoliths: An experimental test with guppies (Poecilia reticulata). Canadian Journal of Fisheries and Aquatic Sciences 46 (1): 108-112. DOI: 10.1139/f89-014

Talwar P.K., Jhingran A.G. 1991. Inland Fishes of India and Adjacent Countries. Oxford and IBH Publishing Co. New Delhi, India.

Worthington D.G., Doherty P.J., Fowler A.J. 1995. Variation in the relationship between otolith weight and age: Implication for the estimation of age of two tropical damselfish (Pomacentrus moluccensis and P. wardi). Canadian Journal of Fisheries and Aquatic Sciences 52 (2): 233-242. DOI: 10.1139/f95-023

Received: 17 November 2017

Accepted: 2 June 2018

Published electronically: 30 September 2018 